\title{
Initial difficulties with breastfeeding technique and the impact on duration of exclusive breastfeeding
}

\author{
Gessandro Elpídio Fernandes Barbosa 1 \\ Janeide M. Pereira 2 \\ Marianne S. Soares 3 \\ Luciana Barbosa Pereira 4 \\ Lucinéia Pinho 5 \\ Antônio Prates Caldeira 6
}

\author{
1,6 Departamento de Saúde da Mulher e da Criança. Universidade de Montes Claros. Av. Rui Braga. Prédio 6. Campus Universitário Darcy Ribeiro. Montes Claros, MG, \\ Brasil. CEP: 39.401-089. E-mail: antonio.caldeira@unimontes.br \\ 2-4 Departamento de Enfermagem. Universidade de Montes Claros. Montes Claros, MG, Brasil. \\ 5 Centro de Ciências Biológicas e da Saúde. Universidade de Montes Claros. Montes Claros, MG, Brasil.
}

\begin{abstract}
Objectives: the present study aimed to evaluate the influence of initial difficulties in breastfeeding on duration of exclusive breastfeeding.

Methods: a prospective study with follow up of nursing mothers and their babies in the first six months of age. The studied population was randomly selected among the Brazilian public health system (SUS, Portuguese acronym) users in three hospitals. The breastfeeding observation protocol was used to collect initial data, which also included socio-demographic, prenatal assistance, delivery care, the postpartum period and the newborn variables. After hospital discharge, data were collected by phone. The multiple regression model was used for statistical analysis.

Results: 175 mother-baby binomials were followed. Problems with breasts during the postpartum hospital stay ( $p=0.030 ; O R=2.38 ; C 195 \%=1.02-5.48)$, maternal work outside home ( $p=0.027 ; O R=2.12 ; C 195 \%=1.03-4.31)$ and low maternal schooling level $(p=0.017$; $O R=2.13 ; C 195 \%=1.10-4.06)$ were shown to be associated with the early interruption of exclusive breastfeeding before the child has completed 6 months of age. A family income lower than one minimum wage was a protective factor $(p=0.048 ; O R=0.42 ; C 195 \%=0.17$ 0.97).

Conclusions: socioeconomic aspects and difficulties in breastfeeding associated with problems with the puerperal breasts stood out as factors which restrict the duration of exclusive breastfeeding.

Key words Breastfeeding, Lactation disorders, Risk factors
\end{abstract}

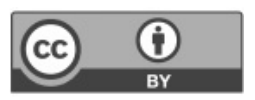




\section{Introduction}

Breastfeeding is a process that involves not only the baby feeding but the formation of a deep affective bond between mother and baby, generating irrefutable benefits to both. ${ }^{1,2}$ The exclusive breastfeeding (EBF) up to six months after birth has a relevant role in reducing child morbidity and mortality by decreasing the chances of several common childhood diseases (e.g., diarrheas and pneumonia).3,4 Breastfeeding is advocated by the World Health Organization (WHO) and Brazilian Ministry of Health as exclusive for the first six months of age and maintained with complementary foods up to two years of age or more. 5,6

Despite the various incentives for breastfeeding in Brazil, EBF indicators are still below desired levels. 7,8 There are several factors involved in this process and the initial difficulties with breastfeeding technique, although little studied, might be among the main facilitators of the early weaning. 9,10 The proper mother-baby binomial positioning during breastfeeding is a fundamental step for the correct latch to occur, in order to avoid possible nipple traumas that hinder or even prematurely interrupt the breastfeeding process. ${ }^{11}$ In this perspective, the United Nations Children's Fund (Unicef) proposed a protocol for observation of breastfeeding process in order to monitor and track the main associated difficulties. 12

Although the proposed instrument is very useful, reports of its use are scarce in literature. Without a careful evaluation of the breastfeeding technique, studies tend to underestimate the initial difficulties associated with this process. Therefore, the importance of a correct latch, mother-baby positioning, breast and nipple conditions, emotional relationships and baby's response to the breast contact is, many times disregarded in the evaluation of the factors that contribute to early breastfeeding interruption. Thus, the present study aimed to evaluate the influence of initial breastfeeding difficulties on duration of exclusive breastfeeding.

\section{Methods}

It is a prospective, observational and analytical study performed from January to December 2015, in a northern city of Minas Gerais state, Brazil. The city, with about 400,000 inhabitants, is the main regional urban center, and despite having the highest Municipal Human Development Index in the region, has indicators that highlight the need for greater investments: $15.9 \%$ of individuals aged 15 years old or more without educational instruction and low per capita income (US\$ 167,10).13 The city has three Baby-friendly hospitals, which offer delivery assistance care, whose users are mainly supported by public service (Unique Health System - SUS). The present study evaluated mother-baby binomials in the first 18 to 48 hours postpartum. Binomials were randomly allocated and posteriorly contacted for the breastfeeding pattern evaluation over the first six months.

For the sample size calculation, the following parameters were considered: $95 \%$ confidence level, $80 \%$ study power, $2: 1$ non-exposed/exposed proportion, results/outcomes (early weaning) between nonexposed $(50 \%)$ and estimated risk of 1.5 . These parameters required a follow up of at least 150 motherbaby binomials. To this value, $15 \%$ was added in regard of eventual losses.

Mother-baby binomials who received postpartum care by public service (SUS) in either one of the hospitals in town, discharged from the hospital together, with exclusive breastfeeding and without supplementary feeding prescription for home use, were eligible for the study. Only mothers with term pregnancy, resident in the urban area and those in good health conditions, according to clinical records, to respond to the initial survey, were included in the study. Regarding the newborns, those with good health conditions and with exclusive breastfeeding at the initial interview, and even those who previously received supplements via medical prescription, were included in the study. Good health conditions were considered as self-reported by the mothers that did not have complaints regarding the babies or themselves nor registered in the clinical records. Mothers pregnant with twins, mothers that eventually did not received immediate postpartum assistance (home birth) and those whose babies were not kept in hospital accommodation were excluded.

Days and shifts, as well as hospitals chosen for data collection, were randomly and proportionally selected according to the monthly number of deliveries in each institution. In each visited shift, all binomials that fit the study criteria were invited to the research.

Data were collected in two phases. Firstly, an initial evaluation of the binomials from 18 to 48 hours postpartum in a joint accommodation environment was performed, and the following was recorded: socio-demographic, prenatal, delivery, newborn and immediate puerperium characteristics. Secondly, information regarding the breastfeeding status, usage of pacifiers or baby bottles and possible complications with breasts and infant's health. This 
information was collected at $15,30,60,90,120,150$ and 180 days postpartum, with an oscillation of about five days on each interval.

Two previously trained nursing students responsible for the initial and following contacts conducted the evaluations, exclusively, with the mothers. To avoid losses, during the first assessment, all the phone contacts available to the mother, including relatives, neighbors, and friends, were collected. Training for the data collection was performed in a practice environment with guidelines which included as from the approach to the mothers to the orientations for inadequate behaviors correction, besides rigorous observation of the breastfeeding technique. Training period was extended until consensus was reached by all group members and was conducted by an obstetric nurse (university professor) experienced in the subject, who is also monitor for training course of Baby-friendly Hospital Initiative and for the course of Breastfeeding Counseling.

The selection of a restrict number of evaluators (both women), aimed to ensure greater results reliability and adherence to the research project.

The instrument used for the data collection included a breastfeeding observation form, which addresses diverse favorable and unfavorable behaviors to breastfeeding, including the binomial positioning during the breastfeeding, the establishment of affective bonds between mother and child, breast anatomical characteristics, the suction efficiency, the binomial response when initiating breastfeeding, as well as the breastfeeding duration and its closure. Breast problems were considered present when the following characteristics were observed: engorged and firm breasts, flat or inverted nipples, breasts or nipples with excoriations, and fissures or redness. The record was filled via direct breastfeeding observation, with the mother's consent. Additionally, the following variables were collected: socio-economic and demographic, maternal health history, parity, and prenatal, delivery, puerperal and newborn assistance.

Breastfeeding survival curves were constructed with the aid of electronic spreadsheets. Statistical analyses were conducted at the Statistical Package for Social Sciences - SPSS software (version 18) (SPSS Inc., Chicago, IL, USA). All variables were assessed descriptively via absolute and relative frequencies.

The associations between the studied variables and exclusive breastfeeding at the sixth month were investigated by bivariate analysis, via chi-square test, and those associated up to $20 \%$ level $(p<0.20)$ were assessed by multiple logistic regression. The variables with $5 \%$ significance $(p<0.05)$ accompanied by their respective odds ratio and $95 \%$ confidence intervals were included in the final model.

The present research project was approved by the Research Ethics Committee (Process No. 844.557), and all the participating mothers agreed to the research and signed the free and informed consent form.

\section{Results}

175 binomials (mother-baby) participated in the present study. Most mothers were aged from 20 to 29 years old $(66.9 \%)$, with brown self-reported skin color $(69.7 \%)$ and without a job outside home $(64.6 \%)$. More than half interviewed reported the familiar income up to a minimum wage $(54.3 \%)$ and schooling up to eight years $(57.7 \%)$. The main demographic and socio-economic characteristics of the participating mothers are described in Table 1

The gestational, prenatal, and newborn-related characteristics are presented in Table 2. The percentage of primiparous women was $42.9 \%$. It was observed that most women attended more than six prenatal appointments. The proportion of operative deliveries (cesarean sections) was $46.3 \%$. Most newborns weighted from 2,500 to 3,500 grams (69.1\%) and the percentage of newborns breastfed at the first hour of life was $53.7 \%$. The use of infant formula during the hospital stay was reported by $24.6 \%$ of the mothers participating in the study. The main initial difficulties on breastfeeding were: inadequate newborn response to breast contact $(20.0 \%)$ and breasts problems $(26.3 \%)$.

Figure 1 presents the survival curves of total breastfeeding (TBF), the sum of predominant and exclusive breastfeeding (PBF + EBF) and exclusive breastfeeding (EBF) for the first six months of life of the studied group. At the end of 180 days of life, $61.2 \%$ of the children were still breastfeeding. In the same period, the prevalence of predominant and exclusive breastfeeding was $39.8 \%$, and the percentage of exclusively breastfed $24.0 \%$.

Table 3 shows the results of the bivariate analysis between the maternal socio-demographic characteristics, prenatal and puerperium assistance aspects and exclusive breastfeeding. The variables with up to $20 \%$ significance association level $(p<0.20)$ were submitted to joint analysis via multiple regression. The variables that remained statistically significant after multiple analyzes were associated with a higher chance of early breastfeeding interruption: maternal work outside home $(p=0.027 ; \mathrm{OR}=2.12 ; \mathrm{CI} 95 \%=1.03-4.31)$, problems 
Demographic and socioeconomic characteristics of nursing mothers. Montes Claros (MG), 2015.

\begin{tabular}{|c|c|c|}
\hline Variable & $\mathbf{N}$ & $\%$ \\
\hline \multicolumn{3}{|c|}{ Maternal age (years) } \\
\hline$<20$ & 18 & 10.3 \\
\hline $20-29$ & 117 & 66.9 \\
\hline $30-39$ & 39 & 22.3 \\
\hline$\geq 40$ & 1 & 0.6 \\
\hline \multicolumn{3}{|c|}{ Self-reported skin color } \\
\hline White & 20 & 11.4 \\
\hline Black & 22 & 12.6 \\
\hline Yellow & 11 & 6.3 \\
\hline Brown & 122 & 69.7 \\
\hline \multicolumn{3}{|c|}{ Working (paid) outside home } \\
\hline Yes & 62 & 35.4 \\
\hline No & 113 & 64.6 \\
\hline \multicolumn{3}{|c|}{ Family income (in minimum wages)* } \\
\hline$\leq 1$ & 95 & 54.3 \\
\hline $1-2$ & 45 & 25.7 \\
\hline$>2$ & 35 & 20.0 \\
\hline \multicolumn{3}{|c|}{ Marital status } \\
\hline Single & 58 & 33.1 \\
\hline Married & 113 & 64.6 \\
\hline Divorced & 4 & 2.3 \\
\hline \multicolumn{3}{|c|}{ Father lives together } \\
\hline Yes & 131 & 74.7 \\
\hline No & 44 & 25.1 \\
\hline \multicolumn{3}{|c|}{ Mother educational level (Years concluded) } \\
\hline$\leq 4$ & 23 & 13.1 \\
\hline $5-8$ & 78 & 44.6 \\
\hline$\geq 9$ & 74 & 42.3 \\
\hline \multicolumn{3}{|c|}{ Residents per household } \\
\hline$\leq 4$ & 119 & 68.0 \\
\hline $5-7$ & 45 & 25.7 \\
\hline$>7$ & 11 & 6.3 \\
\hline
\end{tabular}

* Current minimum wage $=$ US\$202.57.

with breasts during the postpartum hospital stay $(p=0.030 ; \mathrm{OR}=2.38 ; \mathrm{CI} 95 \%=1.02-5.48)$ and low maternal schooling $(p=0.017 ; \quad \mathrm{OR}=2.13$; $\mathrm{CI} 95 \%=1.10-4.06)$. Family income lower than the minimum wage was considered a protective factor $(p=0.048 ; \mathrm{OR}=0.42 ; \mathrm{CI} 95 \%=0.17-0.97)$.

\section{Discussion}

The present study evidenced an elevated frequency of breastfeeding interruption in the first months of life among the evaluated binomials. Breast problems observed during the postpartum hospital stay were among the main factors associated with early breastfeeding interruption, even after the joint analysis with other factors.

Other authors have pointed problems with the breasts as important factors for the EBF interruption. ${ }^{14}$ Breast engorgement, mastitis, nipple fissure or wound, as well as pain and formation of breast abscesses are problems that might be faced during breastfeeding. 15,16 A study performed in the south of Brazil demonstrated that the incidence of breast lesions in maternity had reached a proportion of 
43.6\%. ${ }^{11}$ Problems with the breast, such as engorgement and pain, are among the main elements that, according to the maternal perception, affect the breastfeeding process. 14,17

Some conditions are pointed as likely contributors for the occurrence of breast problems. Coca et al., 18 in a case-control study performed in a University Hospital in 2004/2005, demonstrated that both the binomial position and the latch might contribute to the occurrence of nipple lesions, and the variables statistically associated to this conclusion were: "child with a twisted neck, chin distant

\section{Table 2}

Mothers gestational and prenatal care aspects and newborn characteristics. Montes Claros (MG), 2015.

\begin{tabular}{|c|c|c|}
\hline Variables & $\mathbf{N}$ & $\%$ \\
\hline \multicolumn{3}{|l|}{ Regarding the mothers } \\
\hline \multicolumn{3}{|c|}{ Number of pregnancies } \\
\hline 1 & 75 & 42.9 \\
\hline $2-3$ & 75 & 42.9 \\
\hline$\geq 4$ & 25 & 14.2 \\
\hline \multicolumn{3}{|l|}{ Type of childbirth } \\
\hline Natural & 94 & 53.7 \\
\hline Cesarean section & 81 & 46.3 \\
\hline \multicolumn{3}{|c|}{ Number of appointments (prenatal) } \\
\hline$<6$ & 20 & 11.4 \\
\hline $6-9$ & 109 & 62.3 \\
\hline$>9$ & 46 & 26.3 \\
\hline \multicolumn{3}{|c|}{ Health support during prenatal } \\
\hline Public & 137 & 78.3 \\
\hline Private & 16 & 9.1 \\
\hline Both & 22 & 12.6 \\
\hline \multicolumn{3}{|c|}{ Breastfeeding orientations during prenatal care } \\
\hline Yes & 102 & 58.3 \\
\hline No & 73 & 41.7 \\
\hline \multicolumn{3}{|c|}{ Breast care orientations during prenatal care } \\
\hline Yes & 93 & 53.1 \\
\hline No & 82 & 46.9 \\
\hline \multicolumn{3}{|c|}{ Breastfeeding orientations in the Maternity } \\
\hline Yes & 80 & 45.7 \\
\hline No & 95 & 54.3 \\
\hline \multicolumn{3}{|c|}{ Regarding the newborns } \\
\hline \multicolumn{3}{|l|}{ Baby sex } \\
\hline Male & 81 & 46.3 \\
\hline Female & 94 & 53.7 \\
\hline \multicolumn{3}{|c|}{ Weight at birth (grams) } \\
\hline$<2500$ & 5 & 2.9 \\
\hline $2500-3500$ & 121 & 69.1 \\
\hline$>3500$ & 49 & 28.0 \\
\hline \multicolumn{3}{|l|}{ APGAR 1 minute } \\
\hline$\leq 8$ & 118 & 67.4 \\
\hline 9 & 55 & 31.4 \\
\hline 10 & 2 & 1.1 \\
\hline
\end{tabular}


Table 2

conclusion

\begin{tabular}{lcc}
\hline \multicolumn{2}{l}{ Mothers gestational and prenatal care aspects and newborn characteristics. Montes Claros (MG), 2015.} \\
\hline Variables & $\mathbf{N}$ & $\%$ \\
\hline APGAR 5 minutes & 27 & 15.4 \\
$\leq 8$ & 134 & 76.6 \\
9 & 14 & 8.0 \\
10 & & \\
Time to the first breastfeeding (minutes) & 65 & 37.1 \\
$\leq 30$ & 29 & 16.6 \\
$31-60$ & 81 & 46.3 \\
$>60$ & & \\
Maternity infant formula use & 43 & 24.6 \\
Yes & 132 & 75.4 \\
No & & \\
Initial difficulties (Breastfeeding evaluation form) & 10 & 5.7 \\
Inadequate position & 35 & 20.0 \\
Response to the breast contact & 23 & 13.1 \\
Inadequate latch & 46 & 26.3 \\
Breast problems & 11 & 6.3 \\
Emotional difficulties & & \\
\hline
\end{tabular}

Figure 1

Breastfeeding survival curves; Montes Claros (MG), 2015.

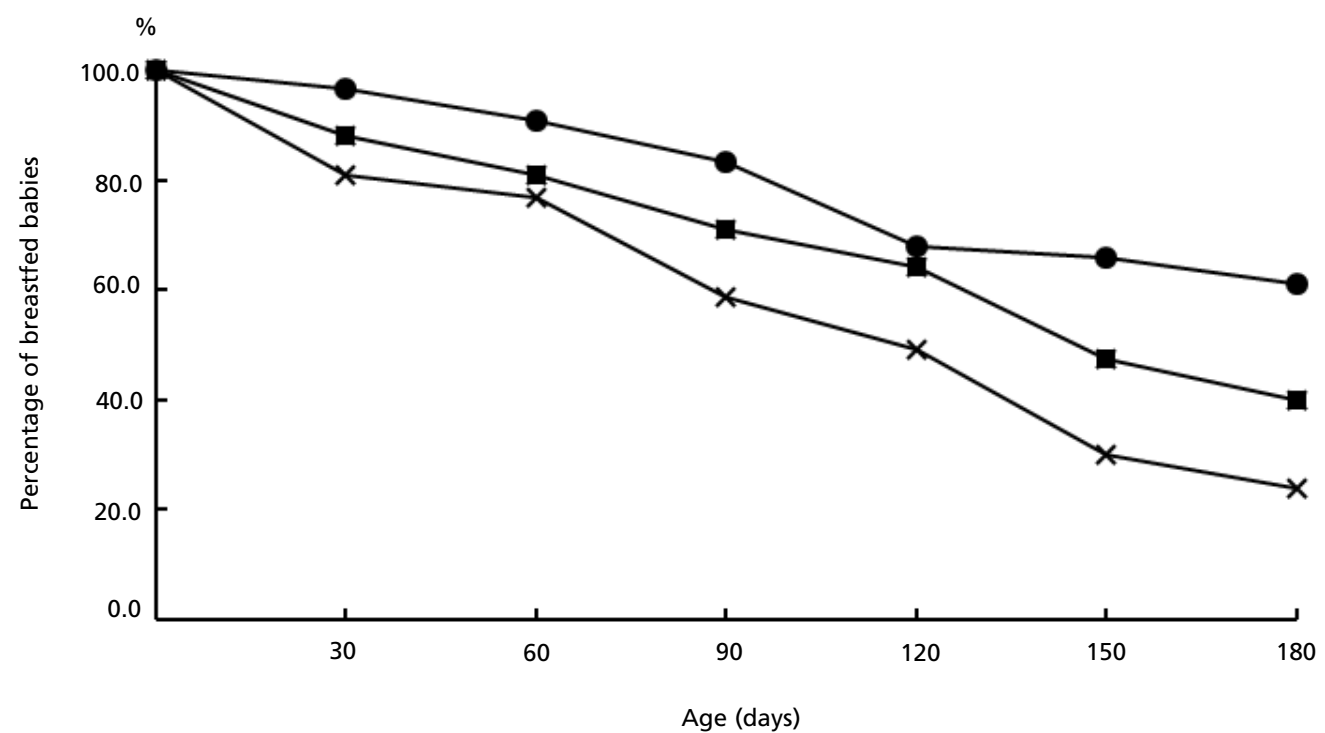

$-\mathrm{TBF} \longrightarrow \mathrm{PBF}+\mathrm{EBF} \quad \longrightarrow$

$\mathrm{TBF}=$ total breastfeeding; $\mathrm{PBF}+\mathrm{EBF}=$ predominant and exclusive breastfeeding; $\mathrm{EBF}=$ exclusive breastfeeding. 
Table 3

\begin{tabular}{|c|c|c|c|c|c|c|}
\hline \multirow[t]{3}{*}{ Variable } & \multicolumn{4}{|c|}{ Exclusive breastfeeding } & \multirow[t]{3}{*}{$p$} & \multirow[t]{3}{*}{ OR (Cl95\%) } \\
\hline & \multicolumn{2}{|c|}{ Yes } & \multicolumn{2}{|c|}{ No } & & \\
\hline & $n$ & $\%$ & $\mathrm{n}$ & $\%$ & & \\
\hline Maternal age & & & & & 0.229 & \\
\hline$>20$ & 37 & 94.9 & 120 & 88.2 & & $2.12(0.56-8.07)$ \\
\hline$\leq 20$ & 2 & 5.1 & 16 & 11.8 & & \\
\hline Working outside the household & & & & & 0.027 & \\
\hline No & 31 & 79.5 & 82 & 60.3 & & $2.13(1.04-4.34)$ \\
\hline Yes & 8 & 20.5 & 54 & 39.7 & & \\
\hline Familiar income (minimum wages) & & & & & 0.001 & \\
\hline$>1$ & 9 & 23.1 & 71 & 52.2 & & $0.36(0.18-0.71)$ \\
\hline$\leq 1$ & 30 & 76.9 & 65 & 47.8 & & \\
\hline Type of childbirth & & & & & 0.702 & \\
\hline Natural & 22 & 56.4 & 72 & 52.9 & & $1.11(0.64-1.95)$ \\
\hline Cesarean section & 17 & 43.6 & 64 & 47.1 & & \\
\hline Marital status & & & & & 0.945 & \\
\hline Married & 25 & 64.1 & 88 & 64.7 & & $0.98(0.55-1.74)$ \\
\hline Singles & 14 & 35.9 & 48 & 35.3 & & \\
\hline Maternal educational level (years) & & & & & 0.017 & \\
\hline$>8$ & 29 & 74.4 & 72 & 52.9 & & $2.13(1.11-4.08)$ \\
\hline$\leq 8$ & 10 & 25.6 & 64 & 47.1 & & \\
\hline Primiparity & & & & & 0.529 & \\
\hline No & 24 & 61.5 & 76 & 55.9 & & $1.20(0.68-2.13)$ \\
\hline Yes & 15 & 38.5 & 60 & 44.1 & & \\
\hline Prenatal care & & & & & 0.126 & \\
\hline Private & 5 & 12.8 & 33 & 24.3 & & $0.53(0.22-1.26)$ \\
\hline Public (SUS) only & 34 & 87.2 & 103 & 75.7 & & \\
\hline Breastfeeding orientations during prenatal care & & & & & 0.081 & \\
\hline Yes & 18 & 46.2 & 84 & 61.8 & & $0.61(0.35-1.07)$ \\
\hline No & 21 & 53.8 & 52 & 38.2 & & \\
\hline Breast care orientations during prenatal care & & & & & 0.501 & \\
\hline Yes & 19 & 48.7 & 74 & 54.8 & & $0.83(0.48-1.44)$ \\
\hline No & 20 & 51.3 & 61 & 45.2 & & \\
\hline Breastfeeding orientations in the Maternity & & & & & 0.505 & \\
\hline Yes & 16 & 41.0 & 64 & 47.1 & & $0.83(0.47-1.45)$ \\
\hline No & 23 & 59.0 & 72 & 52.9 & & \\
\hline Maternity formula use & & & & & 0.131 & \\
\hline No & 33 & 84.6 & 99 & 72.8 & & $1.79(0.81-3 ; 98)$ \\
\hline Yes & 6 & 15.4 & 37 & 27.2 & & \\
\hline Breast problems & & & & & 0.030 & \\
\hline No & 34 & 87.2 & 95 & 69.9 & & $2.42(1.02-5.83)$ \\
\hline Yes & 5 & 12.8 & 41 & 30.1 & & \\
\hline Breastfeeding posture & & & & & 0.858 & \\
\hline Adequate & 37 & 94.9 & 128 & 94.1 & & $1.12(0.31-3.99)$ \\
\hline Inadequate & 2 & 5.1 & 8 & 5.9 & & \\
\hline Baby's response to breast contact & & & & & 0.928 & \\
\hline Adequate & 31 & 79.5 & 109 & 80.1 & & $0.97(0.49-1.92)$ \\
\hline Inadequate & 8 & 20.5 & 27 & 19.9 & & \\
\hline Breast latch & & & & & 0.314 & \\
\hline Correct & 32 & 82.1 & 120 & 88.2 & & $0.69(0.35-1.38)$ \\
\hline Incorrect & 7 & 17.9 & 16 & 11.8 & & \\
\hline
\end{tabular}


from the breast and lower lip facing inward." 18 Other factors such as breast engorgement, firstborn, mother without a partner, semi-protruding and/or malformed nipples, and nipple depigmentation were also associated with a higher occurrence of nipple trauma, with a negative impact on breastfeeding. 19

In the present study, other initial difficulties with breastfeeding technique, such as the inadequate positioning of the binomial mother/child, problems with the latch, mother and child interaction and baby response to the contact with the breast were not statistically associated with the interruption of breastfeeding before the newborn has completed 6 months of age. However, these difficulties are recognized and pointed in other studies as variables that might interfere with adequate breastfeeding practice. 9,11

The frequency of initial breastfeeding difficulties in this study was lower than that reported by Carvalhaes et al., ${ }^{9}$ which also used the breastfeeding observation form to compute the frequency of unfavorable behaviors to breastfeeding in women attended at a maternity hospital in public system (SUS). A more recent study conducted in São Paulo registered that approximately one-third of the mothers mentioned difficulties on breastfeeding at hospital discharge and this variable was associated with early weaning. 20 It is possible that the lowest frequencies observed in the present study are due to all binomials had been recruited from Baby-friendly Hospitals. A few studies highlight that in these institutions, a positive increment in breastfeeding incentives (such as breastfeeding initiation, exclusivity, and duration) is observed. The healthcare team in these institutions encourages breastfeeding in the first half hour postpartum and then at free demand, along with the joint accommodation practice, among others. $21-23$

In the present study, other factors were also investigated, and while mother working outside home and low schooling level were associated with the EBF early interruption, low family income was considered a protective factor. The maternal working outside home is an important and limiting variable for the EBF. According to a study performed by Demétrio et al. 24 the mother work is a factor that contributes to the EBF early interruption. Corrêa et al.,25 in a study performed in Florianópolis (SC), demonstrated that those mothers were more likely to introduce foods earlier into the babies' diet. This association may be related to the shorter time these mothers stay in contact with their children, reducing opportunities for breastfeeding.

Other studies already pointed to the intrinsic existent association between maternal schooling level and EBF duration. 17,24-26 In general, mothers with low schooling level tend to interrupt the EBF earlier, probably due to the lack of information about the breastfeeding benefits. These mothers are more vulnerable to cultural and commercial behaviors influence, which compromises EBF. In a recent meta-analysis from national studies on the factors associated with early weaning, the authors observed that schooling plays a relevant role and may be associated with a higher maternal capacity to solve breastfeeding problems and discomforts, as well as greater assimilation of the breast milk benefits. 27

It should be noted in the present study that a family income lower or equal to one minimum wage was a protective factor against the EBF early interruption. Previous studies reported different associations, where lower family income was a risk factor for the breastfeeding early interruption.27,28 Our contradictory findings might be justified by the fact that infant nutritional intake with other milk sources, other than maternal, demand greater financial expenditure for the family, stimulating mothers belonging to low-income families to breastfeed. It was estimated that the mean monthly expenditure of Brazilian families with artificial milk for infants up to six months old varied between $38 \%$ and $133 \%$ of the minimum wage in 2004 , depending on product brand, thus demonstrating the high costs that the interruption of EBF causes. 5 It is worth mentioning that the study was conducted in a period of significant national financial crisis.

Some variables associated with the EBF early interruption identified in other studies were not associated with EBF practices in the present investigation. The mother's guidance during the prenatal period regarding the breastfeeding process or breastfeeding importance, for example, had no statistically significant association with the EBF duration. Other authors, on the other hand, demonstrate that such orientations are essential to mother's decision about breastfeeding beginning and continuity, but may not constitute isolate and punctual activities. ${ }^{29}$ Thus; the observed results point to the health professional's insufficient educational strategies. Indeed, it is not enough to talk to mothers about breastfeeding their babies, highlighting this practice benefits. It is necessary to anticipate difficult situations, to guide the breastfeeding technique adequately and to present solutions to possible problems.

Another important result that drew attention was the low proportion of newborns breastfed in the first half hour of life. However, as the information was verified with mothers, it is possible that the first 
contact of the baby with the breast still in the delivery room has not been appropriately valued. In any case, this result should be considered as a warning sign for the institutions involved in the study.

Some limitations of this study should be considered. We did not analyze the possible previous lactation experiences through which the mothers passed. Some studies have evidenced a correlation between how the breastfeeding has been carried out in previous children and how it will continue with subsequent children, so that past positive experiences, such as the absence of breast problems, tend to increase the duration of breastfeeding. ${ }^{30}$ Another factor to be considered was the prospective contact with the mothers via phone, an approach that is subject to the limitation of the truthfulness of reported facts, if compared to a personal questioning, besides hindering possible interventions. On the other hand, this is one of the few Brazilian studies with longitudinal evaluation of the breast problems impact on the EBF duration. It is relevant to consider the fact that the study was conducted in Baby-friendly hospitals, so the reported findings might not be generalized to other institutions, although this limitation warns for the possibly even worse scenarios of the breastfeeding incentive measures in other institutions.

From the present results, it is possible to observe

\section{References}

1. Unicef (Fundo das Nações Unidas para a Infância). Global Strategy for Infant and Young Child Feeding. Geneva: World Health Organization; 2003.

2. Victora CG, Bahl R, Barros AJD, França GVA, Horton S, Krasevec J, Murch S, Sankar MJ, Walker N, Rollins NC, Lancet Breastfeeding Series Group. Breastfeeding in the 21st century: epidemiology, mechanisms, and lifelong effect. Lancet. 2016; 387(10017): 475-90.

3. Lamberti LM, Zakarija-Grković L, Walker CLF, Theodoratou E, Nair H, Campbell H, Black RE. Breastfeeding for reducing the risk of pneumonia morbidity and mortality in children under two: a systematic literature review and meta-analysis. BMC Public Health. 2013; 13 (3): S18.

4. Hanieh S, Ha TT, Simpson JA, Thuy TT, Khuong NC, Thoang DD, Tran TD, Tuan T, Fisher J, Biggs BA Exclusive breastfeeding in early infancy reduces the risk of inpatient admission for diarrhea and suspected pneumonia in rural Vietnam: a prospective cohort study. BMC Public Health. 2015; 15: S1166.

5. Brasil. Ministério da Saúde. Secretaria de Atenção à Saúde. Departamento de Atenção Básica. Saúde da criança: nutrição infantil: aleitamento materno e alimentação that breastfeeding difficulties, mainly those associated with breast problems and identified in the first postpartum days, are significant factors for the early EBF interruption. This variable remained associated even after regression with socio-demographic and gestational/delivery variables. Orientation regarding the breast milk benefits to the mother-child binomial, and disadvantages of breastfeeding interruption are necessary to increase breastfeeding duration. Recent research highlights the importance of the health team's engagement to monitor breastfeeding practices. It is also essential the professional's capacitation for the proper mother's orientation, by correcting problems and offering resolution techniques for breast problems, both in the hospital and primary care services, considering that the most significant difficulties will be observed in the first days of the child's life.

The present study evidences that the application of an instrument to evaluate the breastfeeding technique, such as the form proposed by Unicef, encourages the proper breastfeeding process management. The mother-baby binomial breastfeeding technique evaluation in the hospital environment may allow the early identification of difficulties, which may favor the establishment of interventions that may decrease the obstacles and extend the exclusive breastfeeding duration.

complementar. Brasília, DF; 2009. n. 23. 112p. (Série A. Normas e Manuais Técnicos).

6. Unicef. Infant and Young Child Feeding: A tool for assessing national practices, policies and programmes. Geneva: World Health Organization; 2003.

7. Brasil. Ministério da Saúde. Secretaria de Atenção à Saúde. Departamento de Ações Programáticas e Estratégicas. Pesquisa de Prevalência de Aleitamento Materno em Municípios Brasileiros. Brasília, DF; 2010. 63p.

8. Venancio SI, Escuder MML, Saldiva SRDM, Giugliani ERJ. A prática do aleitamento materno nas capitais brasileiras e Distrito Federal: situação atual e avanços. J Pediatr (Rio J.). 2010; 86 (4): 317-24.

9. Carvalhaes MABL, Corrêa CRH. Identificação de dificuldades no início do aleitamento materno mediante aplicação de protocolo. J Pediatr (Rio J). 2003; 79 (1): 13-20.

10. Thulier D, Mercer J. Variables Associated With Breastfeeding Duration. Obstet Gynecol Neonatal Nurs. 2009; 38 (3): 259-68

11. Weigert EML, Giugliani ERJ, França MCT, Oliveira LD, Bonilha A, Espírito Santo LC, Köhler CVF. Influência da técnica de amamentação nas frequências de aleitamento 
materno exclusivo e lesões mamilares no primeiro mês de lactação. J Pediatr (Rio J). 2005; 81 (4): 310-6.

12. Unicef (Fundo das Nações Unidas para a Infância). Breastfeeding management and promotion in a babyfriendly hospital: an 18-hour course for maternity staff. New York; 1993.

13. IBGE (Instituto Brasileiro de Geografia e Estatística). [acesso em 12 ago 2017]. Disponível em http://cidades.ibge.gov.br/xtras/perfil.php? codmun=314330

14. Buck ML, Amir LH, Cullinane M, Donath SM. Nipple Pain, Damage, and Vasospasm in the First 8 Weeks Postpartum. Breastfeed Med. 2014; 9 (2): 56-62.

15. Vieira GO, Martins CC, Vieira TO, Oliveira NF, Silva LR. Factors predicting early discontinuation of exclusive breastfeeding in the first month of life. J Pediatr (Rio J). 2010; 86(5): 441-4.

16. Tang L, Lee AH, Binns CW. Factors associated with breastfeeding duration: a prospective cohort study in Sichuan Province, China. World J Pediatr. 2015; 11(3): 232-8.

17. Boccolini CS, Carvalho ML, Oliveira MIC. Factors associated with exclusive breastfeeding in the first six months of life in Brazil: a systematic review. Rev Saúde Pública. 2015; 49: 91.

18. Coca KP, Gamba MA, Silva RS, Abrão ACFV. A posição de amamentar determina o aparecimento do trauma mamilar? Rev Esc Enferm USP. 2009; 43 (2): 446-52.

19. Coca KP, Gamba MA, Silva RS, Abrão ACFV. Factors associated with nipple trauma in the maternity unit. J Pediatr (Rio J). 2009; 85 (4): 341-5.

20. Rocci E, Fernandes RAQ. Dificuldades no aleitamento materno e infl uência no desmame precoce. Rev Bras Enferm. 2014; 67 (1): 22-7.

21. World Health Organization - United Nations Children's Fund (Unicef). Iniciativa Hospital Amigo da Criança: revista, atualizada e ampliada para o cuidado integrado: módulo 1: histórico e implementação. Brasília, DF: Ministério da Saúde; 2008. 78p. Série A. Normas e Manuais Técnicos.

Received on May 17, 2017

Final version presented on May 4, 2018

Approved on July 18, 2018
22. Saadeh R, Casanovas C. Implementing and revitalizing the Baby-Friendly Hospital Initiative. Food Nutr Bull. 2009; 30 (Supl. 2): S225-9.

23. Merten S, Dratva J, Ackermann-Liebrich U. Do BabyFriendly Hospital Influence Breastfeeding Duration on a National Level? Pediatrics. 2005; 116 (5): 702-8.

24. Demétrio F, Pinto EJ, Assis AMO. Fatores associados à interrupção precoce do aleitamento materno: um estudo de coorte de nascimento em dois municípios do Recôncavo da Bahia, Brasil. Cad Saúde Pública. 2012; 28 (4): 641-54.

25. Corrêa EN, Corso ACT, Moreira EAM, Kazapi IAM. Alimentação complementar e características maternas de crianças menores de dois anos de idade em Florianópolis (SC). Rev Paul Pediatr. 2009; 27 (3): 258-64

26. França GVA, Brunken GS, Silva SM, Escuder MM, Venancio SI. Determinantes da amamentação no primeiro ano de vida em Cuiabá, Mato Grosso. Rev Saúde Pública. 2007; 41 (5): 711-8.

27. Pereira-Santos M, Santana MS, Oliveira DS, Nepomuceno Filho RA, Lisboa CS, Almeida LMR, Gomes DR Queiroz VAO, Demétrio F, Oliveira AM. Prevalence and associated factors for early interruption of exclusive breastfeeding: meta-analysis on Brazilian epidemiological studies. Rev Bras Saúde Mater Infant. 2017; 17 (1): 59-67.

28. Cavalcanti LPG, Diniz RLP, Araújo BQ, Soares AKM, Feitosa GP, Machado JRM, Sousa TCS, Pimentel EC. Fatores associados ao consumo precoce de leite de vaca integral por crianças menores de um ano de idade. Rev Bras Promoç Saúde. 2015; 28 (4): 538-46.

29. Almeida ISA, Pugliesi Y, Rosado LEP. Estratégias de promoção e manutenção do aleitamento materno baseadas em evidência: revisão sistemática. Femina. 2015; 43 (3): 97-103.

30. Berra S, Sabulsky J, Rajmil L, Passamonte R, Pronsato J, Butinof M. Correlates of breastfeeding duration in an urban cohort from Argentina. Acta Paediatr. 2003; 92 (8): 952-57. 